\title{
O EMPREGO DE CAMUNDONGO GENETICAMENTE MODIFICADO COMO MODELO DE ESTUDO PARA DOENÇAS CARDIOVASCULARES
}

THE USE OF GENETIC MODIFIED MICE AS A MODEL TO STUDY CARDIOVASCULAR DISEASES

Tais H F de Carvalho ${ }^{1}$, Oswaldo U Lopes ${ }^{2}$

${ }^{1}$ Doutoranda. ${ }^{2}$ Docente. Disciplina de Fisiologia Cardiovascular e Respiratória. Departamento de Fisiologia. Escola Paulista de Medicina - UNIFESP

CORRESPONDÊNCIA: Tais H.F. de Carvalho

Rua Pedro de Toledo, 541 -

Vila Clementino 04039-031 São Paulo/ SP

E-mail: taishfc@fcr.epm.br / FAX: 55-11-55764536

Carvalho THF, Lopes OU. O emprego de camundongo geneticamente modificado como modelo de estudo para doenças cardiovasculares. Medicina (Ribeirão Preto) 2006; 39 (1): 110-116.

RESUMO: Na presente revisão apresentamos dados e elementos sobre o emprego de camundongos no estudo da fisiologia e fisiopatologia cardiovascular. São apontadas as vantagens de seu emprego, como por exemplo, a facilidade de criação e reprodução. Deve se destacar que a possibilidade desses animais serem manipulados por meio da engenharia genética, nos permite obter animais transgênicos, que se caracterizam por manipulação genética visando a introdução de genes de outras espécies, ou, o que é mais comum, a produção de animais knockout. Animais que apresentam deficiência especifica em um gene, não expressando, portanto, determinadas características, como a deficiência do receptor $a_{2 A}$ ou a ausência da enzima nNOS. As metodologias e técnicas necessárias para o estudo cardiovascular desses animais são apresentadas e discutidas. São também demonstrados alguns resultados dentre os já obtidos, com o emprego destes animais e uma breve discussão dos mesmos.

Descritores: Camundongos. Técnicas Cirúrgicas. Barorreflexo. Região Rostroventrolateral do Bulbo.

\section{1- INTRODUÇÃO}

Desde 1963, as doenças cardiovasculares superam as outras causas de morte, sendo responsáveis atualmente por $27 \%$ dos óbitos. Dentre os diversos fatores de risco dessas doenças, a hipertensão arterial (HA) é um dos principais ${ }^{1}$. Em decorrência desse fato, uma vasta gama de pesquisadores têm se dedicado ao estudo da HA.

Historicamente, uma grande parte das pesquisas cardiovasculares foi realizada em animais de laboratório. Um enorme número de modelos animais foi desenvolvido para imitar as enfermidades humanas e, assim, investigar os processos fisiológicos e patológicos envolvidos.

Na última década, as grandes conquistas na genética e biologia molecular abriram novos horizontes para a pesquisa das patologias cardiovasculares e a demanda pelo uso de modelos animais aumentou porque uma enorme parte dos genes é comum a animais e seres humanos ${ }^{2}$. Em virtude do seqüenciamento do genoma humano, o desafio de ligar genes com determinas funções apenas começou.

Assim, importantes linhas de pesquisa adotaram o camundongo como modelo experimental. Esse animal tornou-se um modelo atraente devido ao pe- 
queno tamanho (aproximadamente 10 vezes menor do que o rato), curto período gestacional (em torno de 21 dias), crescimento rápido dos filhotes e baixo custo de manutenção. Além disso, diversos estudos demonstram que os mecanismos fisiológicos dos camundongos são próximos aos observados em humanos ${ }^{3}$, o que torna interessante o seu emprego em pesquisas.

Os avanços na genética molecular estimulam o uso do camundongo pela possibilidade de inativar genes específicos, tornando-o importante ferramenta para a compreensão da fisiologia. Seu emprego abre inúmeras oportunidades de estudo das funções fisiológicas e patológicas de diversas proteínas (regulatórias ou funcionais), de modo que a possibilidade de utilização de inúmeras cepas geneticamente modificadas contribui com valiosas informações para diversas patologias.

Dentre os camundongos modificados geneticamente encontramos os transgênicos e os knockout. As técnicas básicas usadas para a criação dos animais transgênicos são: 1) a inserção de um gene estranho em um oócito fertilizado ou 2) combinação homóloga em células-tronco embrionárias que são introduzidas em um zigoto ${ }^{4,5}$; ou seja, esses animais recebem genes de outro organismo no seu genoma. Os animais em que um particular gene, ou sua função, foi eliminado são chamados de knockout, como por exemplo, os camundongos desenvolvidos por Huang et al., (1993) ${ }^{6}$ que apresentam ausência do gene para a óxido nítrico sintetase neuronal (nNOS). Bibliotecas de células-tronco embrionárias para anulação de gene de camundongos estão sendo desenvolvidas, o que tornará possível uma geração mais rápida de animais knockout e sem a necessidade de análise da estrutura do gene ${ }^{7}$.

Entretanto, apesar de todos os benefícios do uso de camundongo para pesquisa e extensa literatura com estudos in vitro para investigações de mecanismos celulares e registros eletrofisiológicos, há poucos estudos in vivo nesses animais, em parte por dificuldades técnicas associadas ao seu pequeno tamanho (Figura 1), parte por falta de uma banco de dados sobre procedimentos anestésicos e parâmetros fisiológicos basais, além do desafio de monitoramento cardiorrespiratório. Por exemplo, uma perda de aproximadamente $300 \mathrm{~mL}$ de sangue em um camundongo adulto pode causar um choque hipovolêmico e a reposição com salina do volume perdido não é eficiente $^{7}$.

Um ponto relevante a ser considerado em relação ao camundongo é que este animal não deve ser visto simplesmente como um pequeno rato, por isso deve-se ter cautela nas comparações com resultados em ratos. O camundongo é um animal frágil, cuja pressão arterial (PA) é difícil de ser mantida sob anestesia e sua PA, mesmo com intervenções agudas ou crônicas, dificilmente se eleva.

\section{2- PROCEDIMENTOS PARA A ANESTESIA}

A escolha da anestesia para a cirurgia e monitoramento do camundongo é muito importante porque alguns anestésicos podem afetar o sistema cardiovascular e respiratório, entre outros. Assim, todos os pesquisadores devem ter em mente que essa escolha depende não apenas do procedimento a ser realizado, mas também qual sistema está sendo estudado. Camundongos obesos ou mais velhos geralmente necessitam de uma dose reduzida de anestesia.

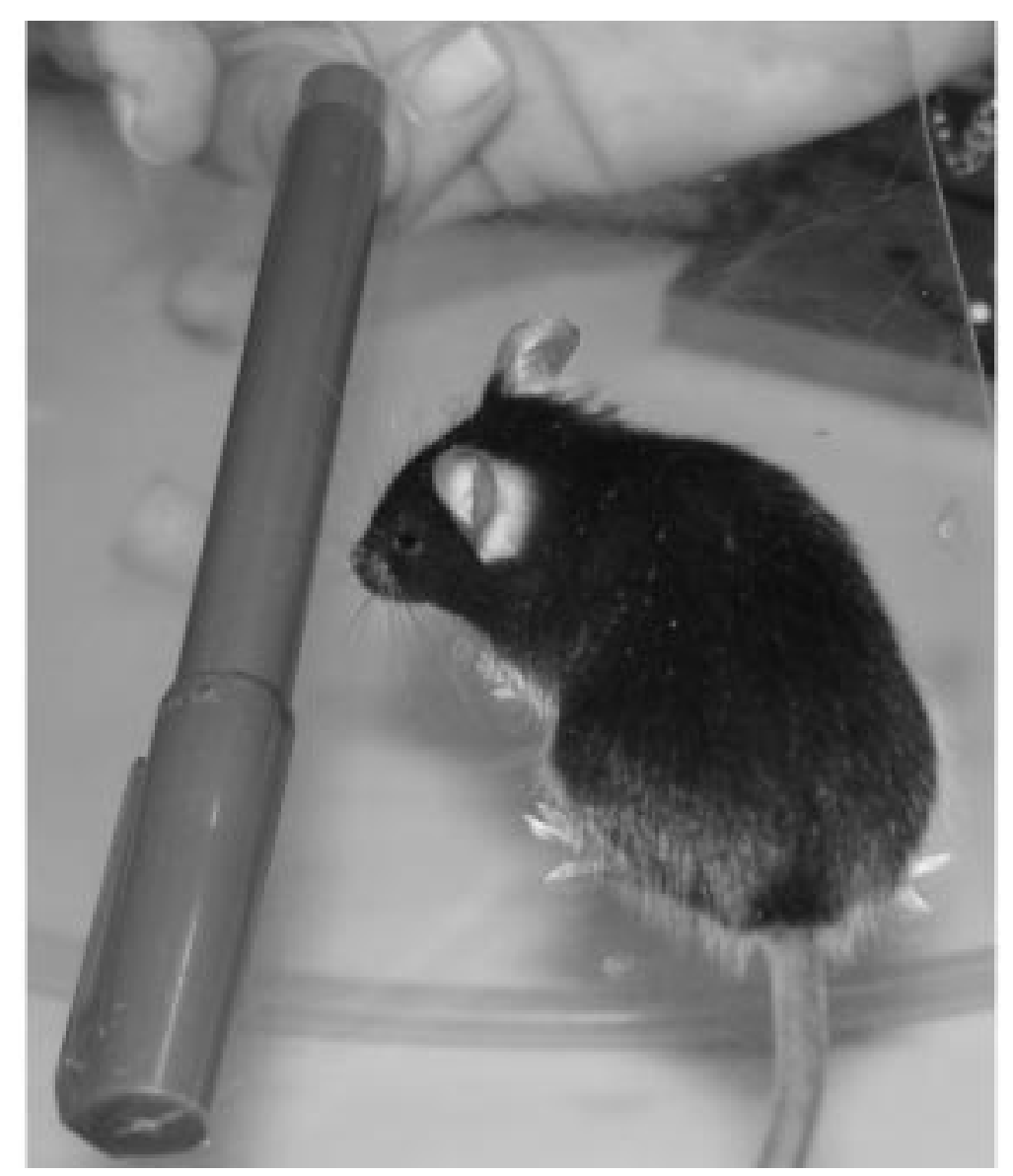

Figura 1: Camundongo $\mathrm{C}_{57} \mathrm{Bl}_{6}$ macho, peso $=27 \mathrm{~g}($ caneta $=13 \mathrm{~cm})$ 
Os anestésicos empregados mais freqüentemente são: pentobarbital $(70 \mathrm{mg} / \mathrm{Kg})$, possibilita um adequado nível anestésico por 30-40minutos, para cirurgias maiores uma suplementação com $30 \mathrm{mg} / \mathrm{Kg}$ se faz necessário durante o procedimento cirúrgico ${ }^{8}$, tiopental, cloralose - uretana, ketamina (associada a xilazina ou diazepam) e anestésicos inalatórios, como halotano ou isoflurano.

A uretana produz um estado estável de anestesia, mas necessita de um período prolongado de recuperação. A uretana combinada com chloralose produz uma mínima depressão no sistema cardiovascular ${ }^{9} \mathrm{e}$ por essa razão vem sendo utilizada nos protocolos deste laboratório.

A associação ketamina - xilazina é bem tolerada, contudo, seu emprego em animais knockout a-adrenérgicos não é eficaz.

Anestésicos inalatórios também podem ser utilizados e permitem excelente controle da profundidade da anestesia. Neste laboratório, utilizamos com sucesso a anestesia com halotano para a realização de pequenas cirurgias. Inicialmente, o animal é colocado em uma câmera anestésica e depois, durante a cirurgia, a anestesia é mantida pelo emprego de uma máscara inalatória (que pode ser confeccionada a partir de uma seringa de $10 \mathrm{~mL}$ cortada e enfaixada com esparadrapo). Os anestésicos inalatórios têm sido vastamente empregados em procedimentos de curta duração devido à sua rápida indução e curto tempo de recuperação.

Esses pequenos animais são mais suscetíveis a hipotermia, por isso o monitoramento da temperatura corporal é essencial e geralmente realizado com o auxilio de almofadas térmicas e termostato.

A traqueostomia pode ser realizada pela inserção de uma cânula intratraqueal. Comumente, permite-se que os animais respirem espontaneamente, mas se necessário pode se utilizar ventilação mecânica. Em geral, é fornecida uma suplementação de $\mathrm{O}_{2}$ aos animais anestesiados para evitar hipóxia. No nosso laboratório utilizamos cânula confeccionada em polietileno para a traqueostomia intratraqueal, com uma conexão entre PE 90 e PE 160, e para ventilação mecânica, um volume de $200 \mathrm{~mL}$ (podendo chegar a $300 \mathrm{~mL}$ quando necessário) e freqüência respiratória em torno de $120 \mathrm{ciclos} / \mathrm{min}$ (se necessário até 170). A respiração espontânea pode ser abolida com o uso de pancurônio $(0.2 \mathrm{mg} / \mathrm{Kg})$. A traqueostomia intratraqueal é realizada pela rápida exposição da traquea por meio de uma pequena incisão no pescoço e posicionamento da cânula visualizando diretamente a área. O monitoramento é importante para evitar um barotrauma. Tam- bém pode ser realizada uma intubação por laringoscopia $^{10}$. O animal é posicionado em uma plataforma com um ângulo de $45^{\circ}$ e um foco de luz é posicionado na altura das cordas vocais. Com o auxilio de um afastador, é possível visualizar claramente a região e posicionar a cânula (PE 90 com a ponta arredonda e cortada em ângulo de $\left.45^{\circ}\right)^{11}$.

\section{3- TÉCNICAS CIRÚRGICAS}

Os principais parâmetros estudados na fisiologia cardiovascular de camundongos adultos são: freqüência cardíaca (FC), pressão arterial média (PAM), debito cardíaco (DC) e eletrocardiograma (ECG). Técnicas invasivas e não-invasivas foram descritas, além de técnicas utilizadas em camundongos nãoanestesiados.

$\mathrm{O}$ registro da PAM se faz necessário para o estudo das funções cardiovasculares e monitoramento durante os procedimentos cirúrgicos. Uma das primeiras técnicas empregadas para registro da PAM foi a pressão de cauda, técnica não invasiva também utilizada em ratos, que consiste na medição da PA sistólica por meio de um esfigmomanomêtro posicionado na cauda do animal ${ }^{12}$. Com o emprego desta técnica, Krege et al. (1995) ${ }^{13}$ observaram, em camundongos $\mathrm{C}_{57} \mathrm{Bl}_{6}, \mathrm{PAM}=119 \pm 4 \mathrm{mmHg}(\mathrm{n}=9)$; Shesely et al. (1996) $)^{14}$, também na linhagem $\mathrm{C}_{57} \mathrm{Bl}_{6}$, notaram $\mathrm{PAM}=121,8 \pm 1,8 \mathrm{mmHg}$ e $\mathrm{FC}=709 \pm 5 \mathrm{bpm}(\mathrm{n}=34)$.

As técnicas invasivas de monitoramento da PA podem ser feitas, por exemplo, pela cateterização da artéria carótida ou femoral associada a transdutores de pressão. Em nosso laboratório, utilizamos a cateterização da carótida para realizar o registro da PAM. Para realizar este procedimento na artéria carótida, utiliza-se um cateter confeccionado com tubo de polietileno, PE 10, e alongado em vapor d'água. Já para a cateterização da artéria femoral pode-se utilizar uma cânula confeccionada em polietileno, com conexão entre PE 10 e PE 08, onde a parte em PE 08 é alongada em vapor d'água também. As cânulas, em ambos os casos, são preenchidas previamente com soro fisiológico. A principal dificuldade da técnica está relacionada ao pequeno tamanho do vaso e a fragilidade das paredes, além disso, a perda de sangue também é uma dificuldade a ser superada no cateterismo. Mattson (1998) ${ }^{15}$ realizou, após 7 dias da cirurgia de cateterismo da artéria femoral, o registro da PAM e FC, em animais da linhagem Swiss Webster (28-44g) não anestesiados, e observou PAM $=116 \pm 1 \mathrm{mmHg}$ e $\mathrm{FC}=627 \pm 21 \mathrm{bpm}(\mathrm{n}=8)$. 
A radiotelemetria é uma técnica que vem sendo utilizada para registro da PA antes, durante e após o período gestacional destes animais ou em animais pesando em torno de $28 \mathrm{~g}$, $22 \mathrm{~g}$ e até menores de $17 \mathrm{~g}^{16,17}$. Faz se uma combinação entre implantação do cateter de pressão na aorta torácica com um transmissor subcutâneo implantado na lateral direita do animal.

Resumidamente, a Tabela I apresenta os valores de PAM e FC obtidos em diferentes linhagens de camundongos por meio das 2 distintas técnicas e observados por diferentes pesquisadores.

O ECG é utilizado para obter FC e parâmetros eletrofisiológicos. Para tanto, implantam-se eletrodosagulha padrão subcutaneamente ou posiciona-se placas diretamente na superfície do átrio ou ventrículo exposto $^{10}$. Em camundongos recém-nascidos, podese realizar o eletrocardiograma utilizando pequenos eletrodos de material adesivo ${ }^{22}$. Kuwaki et al. $(2002)^{23}$ realizaram o ECG em camundongos recém-nascidos utilizando eletrodos (tipo clipe) presos as pernas sob anestesia local (lidocaína em gel), aguardavam um período de 30 minutos inicialmente para então realizar o registro por 20 minutos. Camundongos $\mathrm{C}_{57} \mathrm{Bl}_{6}$ apresentaram P-R $=54 \mathrm{~ms}, \mathrm{QRS}=30 \mathrm{~ms}$ e Q-t $=109 \mathrm{~ms}$. Caracteristicamente, o ECG do camundongo não apresenta um claro segmento ST e a onda T se confunde com o final do complexo $\mathrm{QRS}^{3}$.

Outro parâmetro analisado é o DC, que consiste em um grande desafio. Empregam-se desde métodos de termodiluição ${ }^{21}$ até técnicas não invasivas como o ecocardiograma ${ }^{24}$ e ressonância magnética ${ }^{25}$. O método convencional de termodiluição não é muito prático para camundongos (por ser necessário um lado certo para a canulação e muitas amostras de sangue). A técnica de microesferas tem sido amplamente empregada. Microesferas são introduzidas no ventrículo esquerdo por cateterismo e uma mostra sanguínea é retirada da artéria caudal. Também têm sido utilizados probes ultra-sônicos para a estimativa do débito cardíaco. Para o ecocardiograma é necessário instrumento especializado por causa do pequeno tamanho do coração e elevada FC que esses animais apresentam.

\section{4- ALGUNS RESULTADOS OBSERVADOS}

Nosso laboratório vem, dia a dia, se especializando no uso de camundongos como modelo experimental para estudo da HA. Um dos primeiros passos foi o domínio do registro da PAM e FC que, como explicado anteriormente, está sendo feito pelo cateterismo da artéria carótida. A veia jugular também é canulada para infusão de anestésico ou drogas.

Um dos protocolos inicialmente realizados foi o estudo do barorreflexo em camundongos knockout nNOS. Esse estudo objetivou determinar a influencia da nNOS sobre o ganho barorreflexo (bpm/ $\mathrm{mmHg}$ ). Utilizamos animais controles $\mathrm{nNOS}^{+/+}(\mathrm{n}=12)$ e knockout $\mathrm{nNOS}^{-/-}(\mathrm{n}=11)$, ambos da linhagem $\mathrm{C}_{57} \mathrm{Bl}_{6}$. $\mathrm{O}$ barorreflexo foi avaliado por meio da injeção de fenilefrina (PE: $15-18 \mathrm{mg} / \mathrm{Kg}$ ) e sódio nitroprussiato (SNP: $46-50 \mathrm{mg} / \mathrm{Kg}$ ).

Tabela I: Valores de pressão arterial média (PAM) e freqüência cardíaca (FC) obtidos em diferentes linhagens de camundongos sob distintas técnicas cirúrgicas.

\begin{tabular}{|c|c|c|c|c|}
\hline \multirow{2}{*}{ Linhagens de camundongos } & \multicolumn{2}{|c|}{ CATETERISMO } & \multicolumn{2}{|c|}{ TELEMETRIA } \\
\hline & PAM (mmHg) & $\mathrm{FC}(\mathrm{BPM})$ & PAM (mmHg) & $\mathrm{FC}(\mathrm{BPM})$ \\
\hline Swiss Webster & & & $\begin{array}{c}116 \pm 1^{15} \\
112 \pm 2^{18}\end{array}$ & $\begin{array}{c}627 \pm 21^{15} \\
640 \pm 11^{18}\end{array}$ \\
\hline $\mathbf{A} / \mathbf{J}$ & & & $114 \pm 2^{18}$ & $618 \pm 7^{18}$ \\
\hline $\mathrm{C}_{57} \mathrm{BI}_{6} \mathrm{~J}$ & $\begin{array}{l}106 \pm 2^{20} \\
95 \pm 2 * 21\end{array}$ & $\begin{array}{c}662 \pm 12^{20} \\
462 \pm 21 * 21\end{array}$ & $\begin{array}{l}103 \pm 6^{17} \\
104 \pm 2^{19} \\
110 \pm 2^{18}\end{array}$ & $\begin{array}{c}553 \pm 10^{17} \\
591 \pm 6^{19} \\
594 \pm 9^{18}\end{array}$ \\
\hline $\mathrm{C}_{3} \mathrm{HeBFe} / \mathrm{J}$ & & & $108 \pm 1^{18}$ & $665 \pm 12^{18}$ \\
\hline SWR/J & & & $114 \pm 3^{18}$ & $659 \pm 29^{18}$ \\
\hline
\end{tabular}

* Animais anestesiados 
Os valores basais de $\mathrm{FC}$ não diferiram entre grupos $\left(\mathrm{nNOS}^{-/}\right.$: $604.5 \pm 23.6$ e nNOS $^{+/+}: 618.7 \pm 11.2$ bpm), contudo, os valores basais de PAM nos animais knockout encontravam-se mais elevados $\left(\mathrm{nNOS}^{-/-}\right.$: $112.4 \pm 6.3$ e nNOS $^{++}: 94.8 \pm 3.9$ $\mathrm{mmHg}, \mathrm{P}<.05)$. Tanto o reflexo de bradicardia quanto de taquicardia, provocados pela infusão de nitroprussiato ou de fenilefrina respectivamente, encontravam-se significantemente reduzidos nos animais nNOS $^{-/}$, como demonstrado na Figura 2.

Esses resultados sugerem que a ausência da atividade da nNOS leva ao aumento da PA e que essa enzima é importante na transmissão dos sinais do barorreflexo.

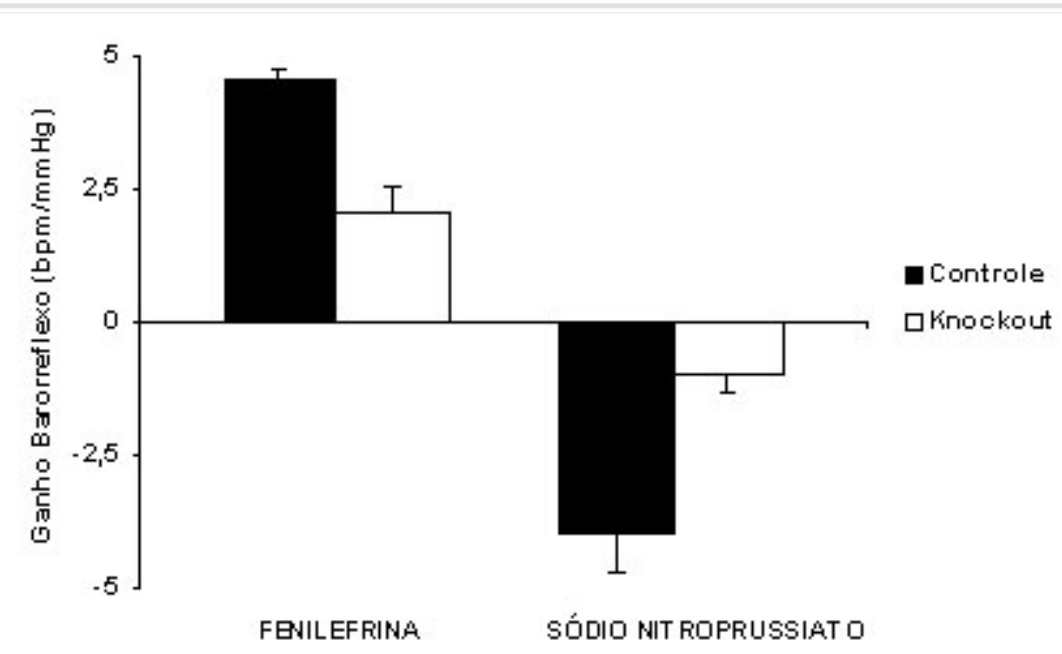

Figura 2: Ganho barorreflexo (bpm/mmHg) em camundongos knockout nNOS e controle promovido pela infusão de fenilefrina ou sódio nitroprussiato. O ganho barorreflexo encontra-se significantemente reduzido nos animais knockout nNOS $\left({ }^{\star} P<0.05\right)$

Os resultados completos desses experimentos, bem como a análise da atividade respiratória desses animais, podem ser encontrados na Autonomic Neuroscience: Basic \& Clinical. 2006 (em publicação) ${ }^{26}$.

Após o domínio dessa técnica, iniciamos protocolos mais elaborados, como o acesso às áreas do sistema nervoso central (SNC) que controlam o sistema nervoso simpático (SNS). Utilizando a experiência com microinjeção de drogas no SNC de ratos, desenvolvemos o método para realizar microinjeções em camundongos, especificamente na região rostroventrolateral do bulbo (RVL), região amplamente conhecida de controle do sistema nervoso simpático ${ }^{27}$.

A droga utilizada foi o L-glutamato $(0,3 \mathrm{nmol}$, $25 \mathrm{~nL}$ ), que nos permitiu mapear a área nos camundongos e depois padronizar a resposta a esse aminoácido excitatório em 3 grupos distintos de camundongos: controles, knockout nNOS e knockout $\mathrm{a}_{2 \mathrm{~A}}$, todos da linhagem $\mathrm{C}_{57} \mathrm{Bl}_{6}$. Os animais foram anestesiados com halotano $\left(1,5 \%\right.$ em $100 \%$ de $\left.\mathrm{O}_{2}\right)$ para cateterismo da artéria carótida e veia jugular. Posteriormente foram anestesiados com uretana $(0,1 \mathrm{~g} / \mathrm{Kg}, \mathrm{IV})$ e choralose $(0,06 \mathrm{~g} / \mathrm{Kg}$, IV) e traqueostomizados. Após essa preparação, os animais eram posicionados em aparelho estereotáxico especifico para camundongos e mantidos aquecidos por meio de um sistema servocontrolado. As microinjeções foram realizadas através de micropipetas de vidro estiradas por calor.

A microinjeção de L-glutamato promoveu um aumento significante na PAM dos 3 grupos: 1) Controles (n=6): de $69 \pm 6$ para $101 \pm 10 \mathrm{mmHg}$; 2) Knockout

nNOS $(\mathrm{n}=4)$ : de $61 \pm 0,5$ para $98 \pm 8 \mathrm{mmHg}$; 3) Knockout $a_{2 A}(n=6)$ : de $76 \pm 5$ para $104 \pm 8 \mathrm{mmHg}$. Estes dados estão visualizados nos gráficos da Figura 3. Não foram observadas alterações estatísticas na $\mathrm{FC}$, sendo que os valores basais observados pelo registro da FC por cateterismo foram: Controle $=530 \pm 28$ bpm; Knockout nNOS $=572 \pm 17$ bpm; Knockout $\mathrm{a}_{2 \mathrm{~A}}$ $=620 \pm 17 \mathrm{bpm}$.

O desenvolvimento desse protocolo objetiva o estudo do SNS em camundongos, especificamente a região RVL, reconhecidamente essencial no controle neural do sistema cardiovascular. A atividade dos neurônios da região RVL é responsável pela geração do tônus simpático ${ }^{27}$, o que conseqüentemente, influencia o controle da PA. Os dados observados, nesse protocolo, assemelham-se aos obtidos em outras espécies, como ratos, anestesiados ${ }^{27}$ ou conscientes ${ }^{28}$, e coe1 hos ${ }^{29}$. Esses dados são preliminares e não evidenciaram diferenças entre os grupos estudados. Ainda não podemos claramente responder se a falta dos receptores $\mathrm{a}_{2 \mathrm{~A}}$ nessa região causa alterações, ou seja, quais alteraçốes podem ocorrer na região RVL pela ausência desse "inibidor" do SNS? Assim como não sabemos se a ausência da nNOS modifica a atividade da região RVL, apesar de já observarmos que essa deficiência altera o controle barorreflexo ${ }^{26}$, possivelmente pela modulação do L-glutamato.

Dessa forma, a ciência começa a olhar para um horizonte ainda não descoberto, repleto de grandes possibilidades e com desafios a serem superados, cujo caminho é claramente bastante promissor. 
120

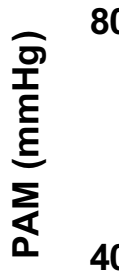

80

0

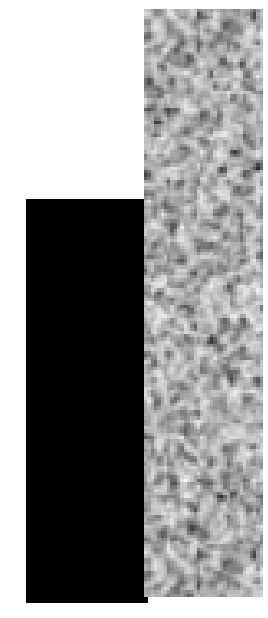

CONT

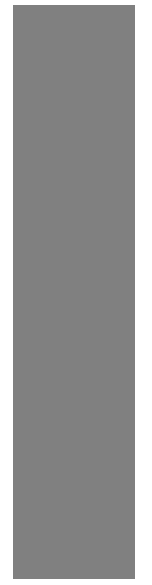

nNOS

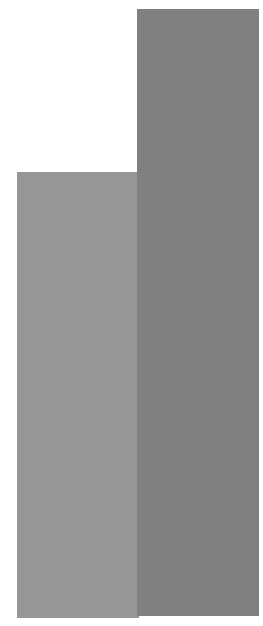

- Pre Glut

Pos Glut

Pre Glut

Pos Glut

Pre Glut

Pos Glut

Figura 3: Resposta da PAM à microinjeção de L-glutamato $(0,3 \mathrm{nmol}, 25 \mathrm{~nL})$ na região rostroventrolateral de camundongos controles, knockout nNOS e knockout alfa 2A. Todos os grupos apresentaram aumento significante de PAM após a microinjeção $\left({ }^{\star} P<0.05\right)$. Não houve diferenças entre as respostas observadas nos distintos grupos.

Carvalho THF. Lopes OU. The use of genetic modified mice as a model to study cardiovascular diseases. Medicina (Ribeirão Preto) 2006; 39 (1): 110-116.

ABSTRACT: This review describes some strategies for the employment of mice in the study of cardiovascular physiology and physiopathology. Among the major advantages of using the mice, we should consider fast reproduction and low maintenance costs. Moreover, the unnumbered possibilities of genetically modification in these animals allow the development of targeted gene mutation, like transgenic mice, characterized by a introduction of a foreign DNA into its genome (knockin), or, more common, the development of knockout mice. These are animals in which a specific gene was disrupted, causing particular characteristics, such as the deficiency of $a_{2 A}$ receptor or the absence of the nNOS enzyme. Methodologies and techniques for cardiovascular research on mice are summarized and discussed and some results, about the use of mice in the cardiovascular study, are also showed in this review.

Keywords: Mice. Surgical Techniques. Baroreflex. Rostral Ventrolateral Medulla.

\section{REFERÊNCIAS}

1 - IV Diretrizes Brasileira de Hipertensão Arterial. Arq Bras Cardiol 2004; 82 (Supl IV).

2 - Braunwald E, Zipes DP, Libby P. Heart diseases. $6^{\text {th }}$ ed. Philadelphia: W. B. Saunders; 2001.

3 - Janssen BJA, Smits JFM. Autonomic control of blood pressure in mice: basic physiology and effects of genetic modification. Am J Regul Integr Comp Physiol 2002; 282: R1545-64.
4 - Rudolph U, Mohler H. Genetically modified animals in pharmacological research: future trends. Eur J Pharmacol 1999; 375: 327- 37.

5 - Williams RS, Wagner PD. Transgenic animals in integrative biology: approaches and interpretations of outcome. J Appl Physiol 2000; 18: 1119-26.

6 - Huang PL, Dawson TM, Bredt DS, Snyder SH, Fishman MC. Targeted disruption of the neuronal nitric oxide synthase gene. Cell 1993; 75:1273-86. 
7 - Rao S, Verkman AS. Analysis of organ physiology in transgenic mice. Am J Physiol 2000; 279: C1-18.

8 - Tarnavski O, Mcmullen JR, Shinke M, Nie Q, Kong S, Izumo S. Mouse cardiac surgery: comprehensive techniques for the generation of mouse models of human diseases and their application for genomic studies. Physiol Genomics 2004; 16: $349-60$.

9 - Dalkara T, Irikura K, Huang Z, Panahian N, Moskowitz MA. Cerebrovascular responses under controlled and monitored physiological conditions in the anesthetized mouse. J Cereb Blood Flow Metab 1995; 15: 631-8.

10 - Berul Cl, Aronovitz MJ, Wang PJ, Mendelsohn ME. In vivo cardiac electrophysiology studies in the mouse. Circulation 1996; 94: 2641-8.

11 - Bromw RH, Walters DM, Greenberg RS, Mitzner W. A method of endotracheal intubation and pulmonary functional assesment for repeated studies in mice. J Appl Physiol 1999; 87: 2362-5.

12 - Van Vliet BN, Chafe LL, Antic V, Schnyder-Candarin S, Montan JP. Direct and indirect methods used to sudy arterial blood pressure. J Pharmacol Toxicol Methods 2000; 44: 361-73.

13 - Krege JH, Hodgin JB, Hagaman JR, Smithies O. Noninvasive computerized tail-cuff system for measuring blood pressure in mice. Hypertension 1995; 25: 1111-5.

14 - Shesely EG, Maeda N, Kim HS, Desai KM, Krege JH, Laubach VE, Sherman PA, Sessa WC, Smithies O. Elevated blood pressure in mice lacking endothelial nitric oxide synthase. Proc Natl Acad Sci 1996: 93: 13176-81.

15 - Mattson DL. Long-term measurements of arterial blood pressure in conscious mice. Am J Physiol 1998; 274: R 564-70.

16 - Carlson SH, Wyss MJ. Long-term telemetric recording of arterial pressure and heart rate in mice fed basal and high $\mathrm{NaCl}$ diets. Hypertension 2000; 35(2): E1-5.

17 - Butz GM, Davisson RL Long-term telemetric measurement of cardiovascular parameters in awake mice: a physiological genomics tool. Physiol Genomics 2001; 5 : 89-97.

18 - Mattson DL. Comparison of arterial blood pressure in different strains of mice. Am J Hypert 2001; 14: 405-8.

19 - Van Vliet BN, Chafe LI, Montani JP. Characteristics of 24h telemetered blood pressure in eNOS-knockout and C57BI/6J control mice. J Physiol 2003; 549: 313-25.
20 - Just A, Faulhaber J, Ehmke H. Autonomic cardiovascular control in conscious mice. Am J Physiol 2000; 279: R2214-21.

21 - Melo LG, Veress AT, Ackermann U, Pang SC, Flynn TG, Sonnenberg $\mathrm{H}$. Chronic hypertension in ANP knockout mice: contribution of peripheral resistance. Regul Pept 1999; 79: 109-15.

22 - Mazel JA, El-Sherif N, Buyon J, Boutjdir M. Electro-cardiographic abnormalities in a murine model injected with IgG from mothers of children with congenital heart block. Circulation 1999; 99: 1914-8.

23 - Kuwaki T, Ishi T, Ju K, Yanagisawa M, Fukuda Y. Blood pressure of endothelin-3 null (-/-) knockout mice and endothelin A receptor null (-/-) knockout mice under anaesthesia. Clin Sci 2002; 103: 485-525

24 - Tanaka N, Dalton N, Mao L, Rockman HA, Peterson KL, Gottshall KR, Hunter JJ, Chien KR, Ross J. Transthoracic echocardiography in models of cardiac disease in the mouse. Circulation 1996; 94: 1109-17.

25 - Wiesmann F, Ruff J, Engelhardt S, Hein L, Dienesch C, Leupold A, Illinger R, Frydrychowicz A, Hiller KH, Rommel E, Haase A, Lohse MJ, Neubauer S. Dobutamine-stress magnetic resonance microimaging in mice: acute changes of cardiac geometry and function in normal and failing murine hearts. Circ Res 2001; 88: 563-9.

26 - Carvalho THF, Lopes OU, Tolentino-Silva FR. Baroreflex responses in neuronal nitric oxide synthase knockout mice (nNOS). Auton Neurosci. In Press

27 - Carvalho THF, Bergamaschi CT, Lopes OU, Campos RR. Role of endogenous angiotensina II on glutamatérgica actions in the rostral ventrolateral medulla in goldblatt hypertensive rats. Hypertension 2003; 42: 707-12.

28 - Martins-Pinge MC, Araujo GC, Lopes OU. Nitric oxidedependet guanylyl cyclase participates in the glutamatérgica neurotransmission within the rostral ventrolateral medulla of awake rats. Hypertension 1999; 34: 748-51.

29 - Horiuchi J, Dampney RAL. 'Dependence of sympathetic vasomotor tone on bilateral inputs from the rostral ventrolateral medulla in the rabbit: role of baroreceptor reflexes. Neurosci Lett 1998; 248: 113-6. 